\title{
A Technological Framework for Teaching-Learning Process of Computer Networks to Increase the Learning Habit
}

\author{
M. Vinay \\ Assistant Professor \\ Department of Computer Science \\ Christ University \\ Bangalore, Karnataka, India
}

\author{
Simna Rassak \\ Research Assistant \\ Christ University \\ Bangalore, Karnataka, India
}

\begin{abstract}
The technological revolution has changed the world. The current generations of people are depended on the digital medium in every aspect of their life. The effectiveness of the digital medium has changed the learner's attitude towards the education system. The rapid growth of technology increased the popularity of ICT (Information and Communication Technology) usage has become unavoidable part of the current education system. The emerging trend in the education technologies has increased the necessity of pedagogical change in higher education.

Computer based courses are one among the import field of study in higher education. In computer courses almost all the subject requires practical knowledge. Even though computer aided learning and technologies are used, there are many subjects which require theoretical knowledge along with practical knowledge. There are many technical topics which are delivered using the traditional classroom based teachinglearning process. Computer Network is one among such subjects. Many times the traditional classroom learning of such subjects create a lack of understanding among student population.
\end{abstract}

The main objective of this paper is to discuss about various teaching and learning method used for Computer-Network teaching-learning process to show the relevance of a pedagogical change in the teaching and learning of this subject. This paper also proposes a technological framework for Computer Networking teaching-learning process.

\section{Keywords}

Teaching-learning Process, ICT, Education Technology, Computer Networks.

\section{INTRODUCTION}

The digital revolution has created a rapid growth in computer technologies, healthcare, business, automobile industry and many other industries. The changing world demands an astonishing knowledge base in the student population. Now requirement of the students to have a firm practical knowledge in essential in order to fit in the digitally growing competitive industry standards. From many research studies educators and researchers understood that an extensive practical knowledge in students is important to increase the students understanding of any subject.

The requirement of efficient education system increased the popularity of Information and communication technology (ICT). ICT has made a great impact in the world within a short span of time. There are many researches happening whole around the world on integration of ICT in education. Many researchers have identified that ICT integration in to the education system is a proficient way to improve the quality of the current education system. Many educators have agreed the fact that the integration of ICT applications in education will provide a facility for student to learn the best possible way [1] [2].

There are many ICT tools and applications in educations. Even though almost all the higher education institutions are following the traditional method of teaching. While there many institutions are using ICT applications in their curriculum example is LMS (Learning Management System), Moodle, MOOC etc have given a mixed result [3] [4].

In the case of Computer specialization courses the usage of technology will show a great impact. In computer major there are many subjects which are taught by the educators using the traditional method of teaching-learning in the classroom. Computer Network is one among such subject. Even though this subject require practical knowledge and understanding from the real life examples, in many institutions this subject is taught through theoretical monotonic lectures. There are very few tools or applications are available which can be used for teaching and learning this subject. Many educators use ICT tools like Power Point Presentation or Video or Animations [5] to teach but it happens very rarely case. If at any ICT tools are used which will be only for delivering the traditional method of theoretical monotonic lectures.

\section{COMPUTER NETWORKS AS A SUBJECT}

Computer Networks is one of the important subjects for computer science students. Teaching Computer Networks course to students were always been a challenge for educators, since the subject require practical understanding more than the theoretical lectures. The main problem of this subject is that the students find it very technical while teaching the theory. Another problem is the content of the subject; example is protocols like TCP/IP, UDP, ATM etc. Protocols are the base of this subject. It also introduces many routing protocols to the students. The main objective of computer network subject in the curriculum is to explain the working of internetworking, its applications and management [6] [7].

Computer networking concepts and protocols are tough for any student to imagine and it is difficult for them to understand the packets, its flow and working of the protocol during the teaching-learning process of the theory. Computer Network as a subject, it is very conceptual and technical. The teaching-learning process of computer networks requires the students to know the basic principles as well as its practical use. In the current teaching method, the understanding of the subject depends on the imagination and visualization of students in their mind while teaching and learning. The main 
problem in teaching this subject is the usage of high amount of jargons. Due to the jargons students may not understand the concepts and this leads to a low level of teacher-student interaction in the classroom [7]. Many times computer networking teaching will become a monolog activity of the teachers in the classrooms. This subject cannot be completely understood without practical knowledge.

\section{EXISTING COMPUTER NETWORK TEACHING-LEARNING METHODS}

The major population of institutions follows a traditional method of teaching when it comes to computer network subject. In traditional teaching and learning students will be listeners in the classroom, in that also very few will be active listeners. But the question is from the listeners how many of them understand the concept. The main reason for this is the absence of an effective application to teach this subject.

\subsection{Power Point Presentation based Teaching-Learning}

Power point presentation based teaching-learning is one of the most commonly followed method of teaching and learning by most of the instructors and leaner's. Many times using this method end up in giving a traditional monotonic lecture. Some rare case instructors may include few examples in the slide, but that may not be giving any exposure to the real working of the networking.

To increase the effectiveness of the teaching-learning process of this subject many institutes experimented various method of delivering the lectures. In that two major methods are problem-based and Project based teaching-learning.

\subsection{Problem Based Teaching-Learning}

Problem-based teaching learning students learn the topic by doing problems related to the same. This can be done individually or in a group. This considered to be a student centric learning. Using this method students share their knowledge and gather more information from others [8] [9].

\subsection{Project Based Teaching-Learning}

Project-based teaching learning process the students will be given project, which they have to complete alone or in a group. They will be given a time period for completing the project it can vary from one week to six months. The project can be assigned to students with the collaboration of third party organization. While collaborating with organization, students will work for the organization in their project. The project can be a task which needs to be completed alone or in a group [10].

The major issue with problem based and project based teaching-learning method is it depends upon the knowledge base of the students, until and unless the students have minimal base knowledge of the concepts they may not understand the problem or project and lead to incompletion.

\subsection{Lab}

Using labs another method of teaching-learning followed by many higher educational institution. But major population of the education institution lacks the proper infrastructure for Computer Network lab. Even if the institution have a lab, the effective use will happen only when the student understand the basic concept.

\subsection{Virtual Lab}

Virtual lab is one of the popular technologies followed by many educational institutions [11]. It is nothing but virtual environment for the labs and virtual labs can be accessed by the user from anywhere that's the only advantage it has.

Even though there are many methods for teaching and learning computer networks, which deliver student-centric learning without the base knowledge of the subject students will find it difficult to learn the computer networks. To resolve this problem there must be an efficient method or an application for teaching and learning computer networks concepts along with these activities.

\section{RESEARCH METHODOLOGY}

The initial step of methodology was data collection, in order understand the existing methods used for teaching and learning computer networks. Data for the study was gathered by distributing a structured questionnaire using google form. MCA, MSc and Engineering students with computer major was the sampling population used for data collection. 150 questionnaires were distributed and 128 response were received. The response rate was $85.3 \%$. The collected data from the respondent were tabulated and analyzed using $\mathrm{R}$.

\subsection{Data Analysis and Result}

To understand the current methods of teaching computer networks and the technologies used in higher education, 18 questions were asked in the questionnaire. Which can be summarized into 6 major questions.

Table 1. Research Questions asked

\begin{tabular}{|c|c|c|c|}
\hline $\begin{array}{c}\text { Sl. } \\
\text { No }\end{array}$ & Question Category & Yes & No \\
\hline Q1 & $\begin{array}{c}\text { Understanding of the } \\
\text { subject }\end{array}$ & $45 \%$ & $55 \%$ \\
\hline Q2 & Relevance of the Subject & $100 \%$ & - \\
\hline Q3 & Practical Learning & $20.31 \%$ & $79.69 \%$ \\
\hline Q4 & $\begin{array}{c}\text { Usage of Real life } \\
\text { example }\end{array}$ & $3.90 \%$ & $96.09 \%$ \\
\hline Q6 & $\begin{array}{c}\text { Recommend New } \\
\text { Technology for learning }\end{array}$ & $100 \%$ & - \\
\hline
\end{tabular}

Research Question 5 was the important question in the category, which helped us to understand the existing methods and technologies.

Table 2. Teaching and Learning methods and technology used Research Questions Q5

\begin{tabular}{|c|c|c|}
\hline $\begin{array}{c}\text { Existing Teaching \& } \\
\text { Learning Facility }\end{array}$ & $\%$ & Count \\
\hline Theory & $75 \%$ & 96 \\
\hline Lab & $9.37 \%$ & 12 \\
\hline Problem Based & $5.46 \%$ & 7 \\
\hline Virtual Lab & $4.68 \%$ & 6 \\
\hline Project Based & $3.90 \%$ & 5 \\
\hline
\end{tabular}


From the fig 1. From the analysis of students responds received, it is evident that the current teaching and learning method of computer networks is completely based on theoretical classroom teaching along with power point presentations. Very few institutions are providing the Lab, Virtual Lab, Problem based or project based learning environment for computer networks learning.

\section{Existing Computer Networks Teaching and Learning}

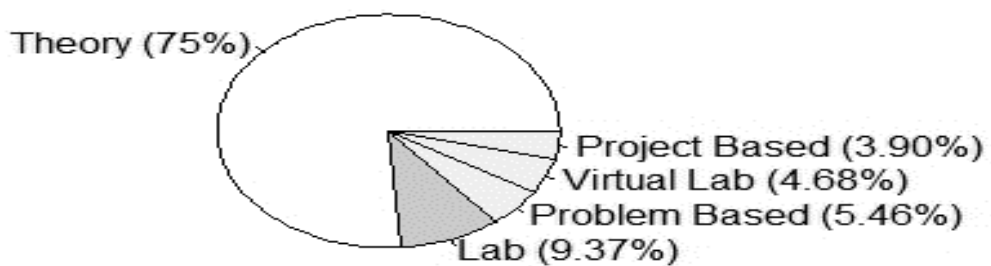

Fig 1: Overall Students Response on the Computer Networks Teaching Methods and Technologies Used

\section{PROPOSED MODEL}

From the study on computer network teaching-learning process followed by institutions, it is evident that the computer network contains the elements of software engineering, electronic and communication technology. Students often develop practical understanding of any subject from observation. The proposed model gives students an opportunity to manipulate their own example along with the theory lectures. This will develop a strong base understanding of networking concepts through their hands own experience.

The application enables the students to generate their own networking models and identify the concepts and the mistake they make. The application gives guide line to the user to reach the correct networking example.

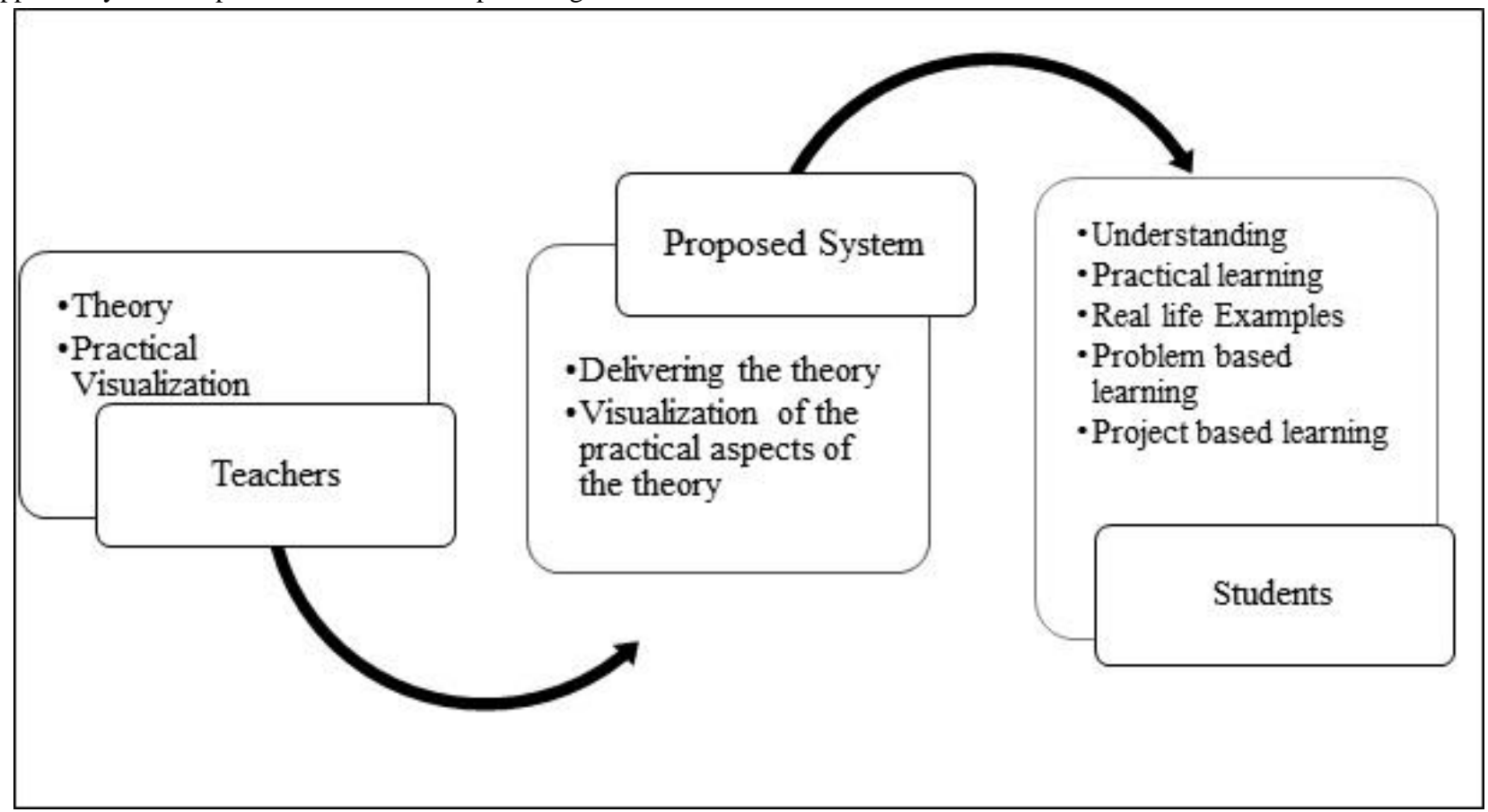

Fig 2: Task Driven Architecture

The major task of the model suggested in this paper is to enable the educator to develop a practical visualization of the networking topic on which they are delivering the theory lectures. The system allows the user to generate their networking model for visualization and discovering the mistakes along with the guide line to correct it. This application gives an opportunity to the students to create their own visual examples of the topic they are learning in the classroom.
The main aim of the projected system is to provide a user interface for both students and teachers to create network related examples. The technological framework has two basic parts. The main part is the web based application which is divided into two basic parts. One carry out the application control of the application and the other part is the application view which allows the user to visualize the contents. The second part of the frame work is the resource manager which is connected to database and allow the user to save the networking examples manipulated by the users. 


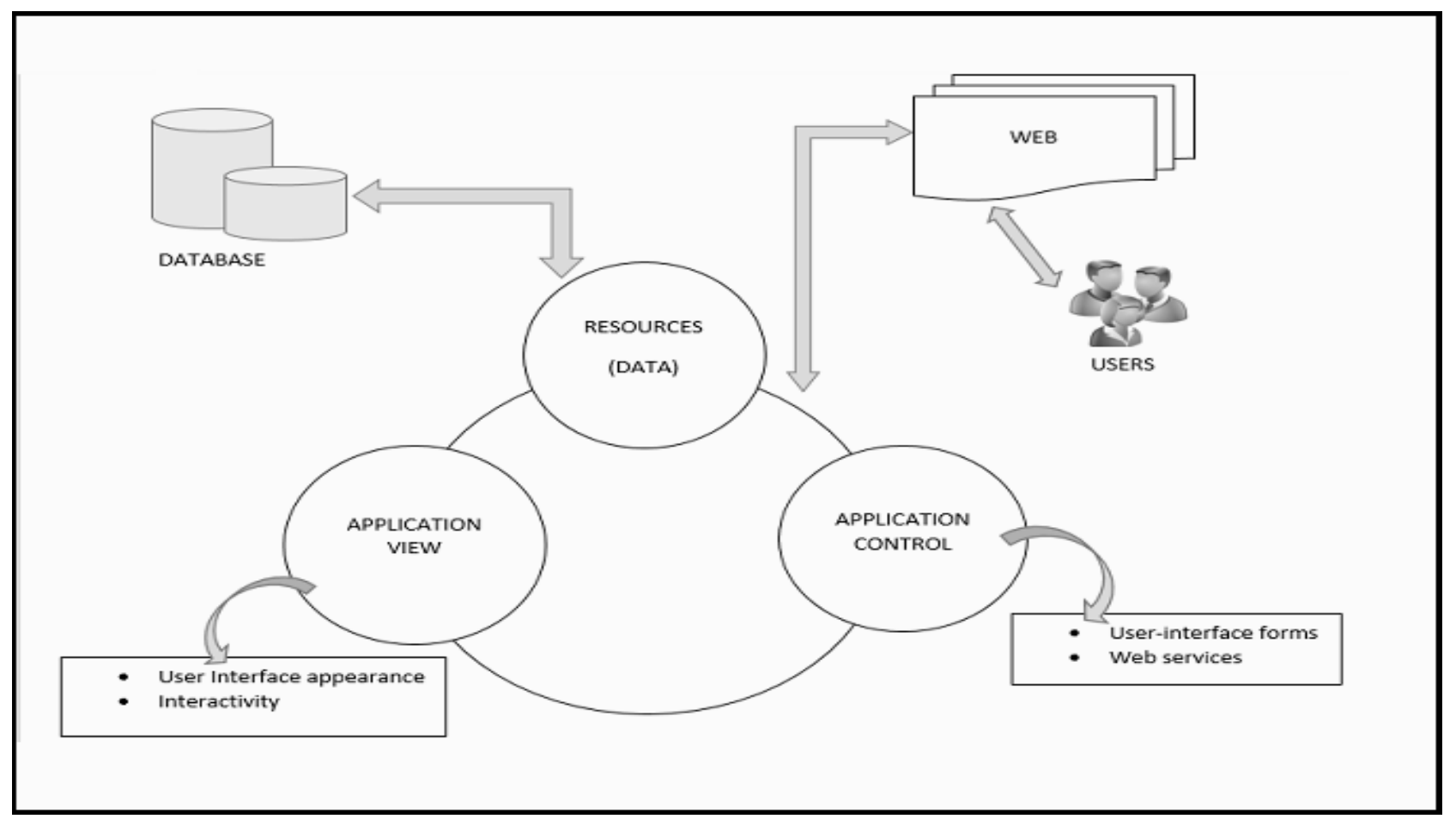

Fig 3: Technological Framework for Computer Network teaching-learning Application

The model is a web based platform. The major advantage of the proposed model is the practical visualization. It will provide a reflective web based content-rich website to acquire theoretical knowledge and practical visualization. There are only few networking application available for teachinglearning process. In the available application most of them are currently used only for the professional certification and they are not used in classroom teaching-learning process in the higher education institutions. The model suggested in this paper is majorly focused for the higher education institutions in order use it along with the classroom lectures.

The model can be used to show the working of networks topic. The major purpose of the design is to develop an application which guides the user about the various requirements of a computer network connection. This application allows the user to manipulate and view a practical networking situation. Visualization will increase the students understanding and it gives an advantage of viewing something that would normally difficult to view. Many networking examples manipulated using this application by educators and students will be there on their textbook as a theoretical concept not as a visual example. Another major advantage of the web based application is the accessibility. The user can access this anytime and anywhere.

The application can be accessed by teachers and students to share the knowledge and learning the subject. When the students understand the concept faster, instructors can save time in the classroom. By saving time from the classroom teaching, teachers can update the teaching content with new developments in the subject and get more time to explain them new concepts. In this new model students play a major role and it will improve the teaching quality. The teachers will be able to deliver blended or flipped classes for students. The teachers will be able to give examples and solve the problems in the class. The students get more time to work on the extra problems. The new model will improve the interactions between students and teachers. In this way teachers will become mentor rather than a lecturer. It will give active and effective participation of students in learning.

The application projected in this paper can complement along with problem-based and project-based learning. The new model can be included along with static and interactive content in teaching. The static contents are the lecture video, e-text book, materials, questions, tests; reference books etc. The interactive contents are the blogs, forum post or the social networking sites.

\section{CONCLUSION AND FUTURE WORK}

The technological boom has changed our society; it has influenced human life to a great extent. One of the major phases of technological revolution is the ICT integration in various fields like industrial work, business, agriculture and various other sectors. ICT usage in the education is one of the major turning point and reason for generating the thought of pedagogical change in many higher education institutions. The main focus of this paper was to discuss about the various computer networking subject teaching-learning methods. The paper also suggests an ICT based web application technological framework for computer-network teachinglearning process.

The future direction of this application is to develop an intelligent web based interface for teaching the entire subject to improve the teaching-learning process. The model proposed in this paper will be the backbone for designing the future system framework for a web based learner and tutor model for delivering computer networks concept effectively. As an extension of the research study a thorough evaluation will be done in order to design a new application to enrich the students learning habit.

\section{ACKNOWLEDGMENTS}

A Technological Framework for Teaching-Learning Process of Computer Networks to Increase the Learning Habit paper is a part of the Major Research Project titled 'Impact of ICT in Teaching Learning Process in Higher Education Institutions'. 
Fully supported and funded by Center for Research Christ University under the Grand No: MRPDC-1211. We would like to thank the Center for Research, Christ University and the Management for their incessant support and opportunity to work on the project. We also would like to thank IJCA and their reviewers for considering and accepting our paper for publishing in the journal.

\section{REFERENCES}

[1] Poulova, P. \& Simonova, I. 2014. "The impact of ICT amongst the secondary school graduates towards higher education". 8th Malaysian conference on Software Engineering. pp: 371-375.

[2] Bouras, A.; Veillard, L.; Tralongo, S. \& Lenir, M. 2014. "Cooperative education development: Towards ICT reference models". International Conference on Interactive Collaborative Learning (ICL). pp: 855-861.

[3] David, F. \& Abreu, R. 2014. "Information technology in education: Recent developments in higher education". 9th Iberian Conference on Information Systems and Technologies (CISTI). pp: 1-6.

[4] Venkatesh, V.; Croteau, A.-M. \& Rabah, J. 2014. "Perceptions of Effectiveness of Instructional Uses of Technology in Higher Education in an Era of Web 2.0". 47th Hawaii International Conference on System Sciences (HICSS). pp: 110-119.

[5] Spence, A. \& McKenzie, S. 2014. "Using interactive technology for lectures in higher education information technology". International Conference on Teaching, Assessment and Learning (TALE). pp: 224-230

[6] Xie, Hongxia. \& Zhong, Qingjiang. 2012. "Design of Basic computer teaching mode based on blended Learning". $14^{\text {th }}$ International Conference on Higher Performance Computing and Communication. pp: 16731676.

[7] Li, Wei. \& Liu, Peixiang. 2011. "Teaching Computer Networks for Distance Computer Science Students: An Instructor's Perspective". International Conference on Electrical and Control Engineering (ICECE). pp: 68146818.

[8] Problem Based Learning. Available at: http://www.wikipedia.org/wiki/problem_based_learning

[9] Linge, Nigel. \& Parsons, David. 2006. "Problem-Based Learning as an Effective Tool for Teaching Computer Network Design". IEEE Transactions on Education. pp: 5-10.

[10] Project Based Learning. Available at: http://www.wikipedia.org/wiki/project_based_learning

[11] Voss, Gleizer B.; Nunes, Felipe B.; Muhlbeier, Andreia R.K. \& Medina, Roseclea D. 2013. "Context-Aware Virtual laboratory for Teaching Computer Networks A proposal in the 3D OpenSim Environment". $X V$ Symposium on Virtual and Augmented Reality. pp: 252255.
[12] Filipovic Tretinjak, M.; Bednjanec, A. \& Tretinjak, M. 2014. "Application of Modern Teaching Techniques in the Education Process". $37^{\text {th }}$ International Convention on Information and Communication Technology, Electronics and Microelectric (MIPRO). pp: 628-632.

[13] Feng, Jian. 2009. "Research on Teaching Reform of Computer Networks Course". $2^{\text {nd }}$ International Conference on Education Technology and Training. pp: 79-82.

[14] Gusev, M.; Ristov, S. \& Donevski, A. 2014. "Integrating practical CISCO CCNA courses in the Computer Networks' curriculum". IEEE Global Engineering Education Conference (EDUCON). pp: 499-506

[15] Liangxu Sun; liansheng Wu; Yujun Zhang \& Hang Yin. 2013. "Comparison between physical devices and simulator software for Cisco network technology teaching". 8th International Conference on Computer Science \& Education (ICCSE). pp: 1357-1360.

[16] Petcu, D.; Iancu, B.; Peculea, A.; Dadarlat, V. \& Cebuc, E. 2013. "Integrating Cisco Packet Tracer with Moodle platform: Support for teaching and automatic evaluation". International Conference Networking in Education and Research $12^{\text {th }} \mathrm{Ed}$. pp: 1-6.

[17] Janitor, J.; Jakab, F. \& Kniewald, K. 2010. Visual "Learning Tools for Teaching/Learning Computer Networks: Cisco Networking Academy and Packet Tracer". Sixth International Conference on Networking and Services (ICNS). pp: 351-355.

[18] Hua Qi. 2014. "Using virtual machine technology to establish NetworkSecurity teaching platform". IEEE Workshop on Electronics, Computer and Applications. pp: 707-709.

[19] Zhong Bocheng; Zizhuo Yang; Yihan Wang \& Runcai Huang. 2014. "Exploration and practice in teaching of digital logic course". 9th International Conference on Computer Science \& Education (ICCSE). pp: 799-802.

[20] Vasileva, S.Z. \& Kulchiar, A. 2014. "Options of GPSS World for integrated demonstration models in the educational process". Conference on Science and Information. pp: 933-937.

[21] Yanchun Gu. 2013. "Study on the design and implementation of the computerdistance education system". International Conference on Mechatronic Sciences, Electric Engineering and Computer (MEC). pp: 2387-2390.

[22] Moh, M.; Alvarez-Horine, R.; Chandawale, S.S. \& Mogarkar, S.A. 2013. "On interdisciplinary student background: A successful course integrating teaching and research". Conference on Interdisciplinary Engineering Design Education Conference (IEDEC). pp: 56-62 